\title{
Oleylamine Assisted Synthesis of Ultralong Copper Nanowires
}

\author{
Michael $\operatorname{Tan}^{1, a}$ and Mary Donnabelle Balela ${ }^{1, b}$ \\ ${ }^{1}$ Sustainable Electronic Materials Group, Department of Mining, Metallurgical and Materials Engineering, University of the Philippines, \\ Diliman, Quezon City 1101
}

\begin{abstract}
This paper reports the hydrothermal synthesis of smooth and ultralong copper nanowires $(\mathrm{Cu} \mathrm{NW})$ prepared using oleylamine (OM), oleic acid (OA), and $\mathrm{Cl}^{-}$ion as coordinating and etching agents respectively. $\mathrm{Cu}$ nanowires with mean diameters around $82.3 \mathrm{~nm}$ and lengths exceeding $300 \mu \mathrm{m}$ were synthesized using $2 \%$ vol. OM and $1.8 \mathrm{mM} \mathrm{OA}$ at $120^{\circ} \mathrm{C}$ after $12 \mathrm{~h}$. The $\mathrm{Cu}$ NWs exhibit five-fold twinning and growth along the [110] direction. The morphological evolution of the products were also observed and discussed. Without $\mathrm{Cl}^{-}$, octahedral crystals instead of nanowires were formed. The addition of oleic acid as coordinating agent resulted to fewer particles and smoother nanowires which exhibit excellent mechanical stability. This method provides a simple, low-cost and high yield synthesis of $\mathrm{Cu}$ NWs for applications such as gas sensors and transparent conducting electrodes.
\end{abstract}

\section{Introduction}

Copper nanowire $(\mathrm{Cu} \mathrm{NW})$ research has attracted considerable attention because of its wide range of applications such as electrical interconnects, photodetectors, field emission devices, microheaters, gas sensors, and as a potential low-cost alternative to indium tin oxide for use as a transparent conducting electrode [13]. Its excellent electrical and thermal conductivity coupled with its abundance makes it a very viable alternative. Among the various methods for $\mathrm{Cu} \mathrm{NW}$ production, a solution-based process allows for a simple, low-cost, and large scale synthesis of free standing $\mathrm{Cu}$ NWs which can be easily collected. Aqueous or organic solvents such as HDA, ODA, SDBS, or CTAB have been used to promote nanowire growth. Morphological control over the nanowires can easily be achieved by simply varying the concentrations of reactants, temperature, and time

Some of the earliest studies of $\mathrm{Cu}$ NWs grown via aqueous synthesis was first reported in 2003 by Liu et. al. using sodium dodecyl benzenesulfonate (SDBS) as the structure directing agent and phospate $\left(\mathrm{HPO}_{3}{ }^{2-}\right)$ as the reducing agent [4]. In 2005, a synthesis method was developed by a Zeng et. al. using a $\mathrm{Cu}$ precursor and ethylene diamine (EDA) in a highly basic solution [5]. They were able to synthesize $\mathrm{Cu}$ NWs with diameters around $90-120 \mathrm{~nm}$ and lengths of $40-50 \mu \mathrm{m}$ after $1 \mathrm{~h}$ of reaction. Since then, a number of synthesis methods have been reported to produce $\mathrm{Cu}$ NWs. While the aqueous synthesis route is proven to be low cost, common problems such as oxidation and long term storage have limited the process from producing it on a large-scale [5,
6]. Moreover, the some have reported tapering along the wires and rough morphologies. These were found to have a significant impact in increasing the electrical resistivity of the $\mathrm{Cu} \mathrm{NW} \mathrm{[7].} \mathrm{In} \mathrm{this} \mathrm{study,} \mathrm{we} \mathrm{present} \mathrm{an} \mathrm{aqueous}$ synthesis route for producing smooth, ultralong, and oxidation stable $\mathrm{Cu}$ NWs using oleylamine and oleic acid as coordinating agents.

\section{Experimental}

In a typical synthesis, a copper solution containing $0.68 \mathrm{~g}$ (40 mM) of $\mathrm{CuCl}_{2}$ salt and $0.792 \mathrm{~g}(40 \mathrm{mM})$ of anhydrous glucose are added into a $250 \mathrm{~mL}$ beaker containing $80 \mathrm{~mL}$ of deionized $\mathrm{H}_{2} \mathrm{O}$. The solution was stirred until the metal salt and glucose were completely dissolved. In a separate $500 \mathrm{~mL}$ Erlenmeyer flask, $8 \mathrm{~mL}$ ( $2 \%$ vol.) of oleylamine (OM), $14 \mathrm{~mL}$ (3.5\% vol.) of ethanol, and varying amounts of $(0.60-1.8 \mathrm{mM})$ of oleic acid (OA) were mixed together. Then, the copper solution was quickly added. Finally, the solution was diluted to $400 \mathrm{~mL}$ using deionized $\mathrm{H}_{2} \mathrm{O}$ and was heated at $50^{\circ} \mathrm{C}$ for $12 \mathrm{hrs}$. After ageing, $100 \mathrm{~mL}$ of the precursor solution was transferred into a Teflon lined autoclave reactor and heated to $120^{\circ} \mathrm{C}$ for varying times.

The morphologies, structure and composition of the obtained products were characterized using high resolution transmission electron microscope (HRTEM, JEOL JEM-ARM200F), scanning electron microscope (SEM, JEOL 5300) and X-ray diffraction (XRD, $\mathrm{Cu} \mathrm{K} \alpha$, Shimadzu XRD-7000) respectively. The reported diameters were taken from measurements of more than 300 wires.

Corresponding author: ${ }^{\mathrm{a}}$ mikertan@gmail.com; ${ }^{\mathrm{b}}$ mdlbalela@gmail.com 


\section{Results and discussion}

Figure 1 shows the SEM images of $\mathrm{Cu}$ NWs formed at $120^{\circ} \mathrm{C}$ and under high pressure using $2 \%$ vol. OM and $0.6 \mathrm{mM}$ OA, taken at different reaction times. After $4 \mathrm{~h}$ of reaction, rectangular-pyramid-like microstructures and very thin nanowires having average diameters of $43 \mathrm{~nm}$ were formed. The pyramidal microstructures are tapered at the ends and have an average base diameter of 3-5 $\mu \mathrm{m}$ as shown in Fig 1a. When the reaction is allowed to proceed further to $8 \mathrm{~h}$, thicker nanowires with an average diameter of $229 \mathrm{~nm}$ were formed together with irregularshaped precipitates as shown in Fig 1b. However, the amount of rectangular-pyramid structures across the solution gradually decreased. After $12 \mathrm{~h}$, only nanowires with average diameters of $82.3 \mathrm{~nm}$ and lengths exceeding $300 \mu \mathrm{m}$ were present in the solution. The wires also exhibit mechanical strength as seen in their ability to withstand bending even at angles greater than $90^{\circ}$. (a) $4 \mathrm{~h}$

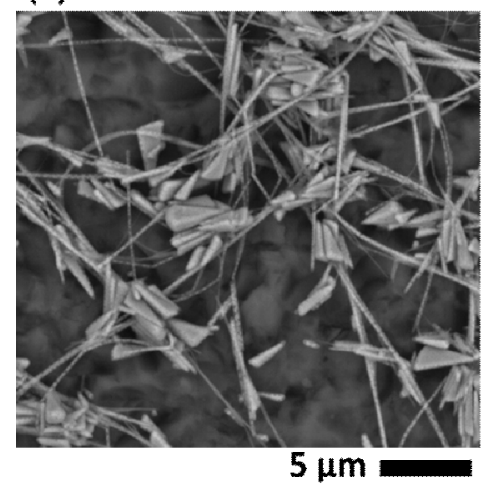

(b) $8 \mathrm{~h}$

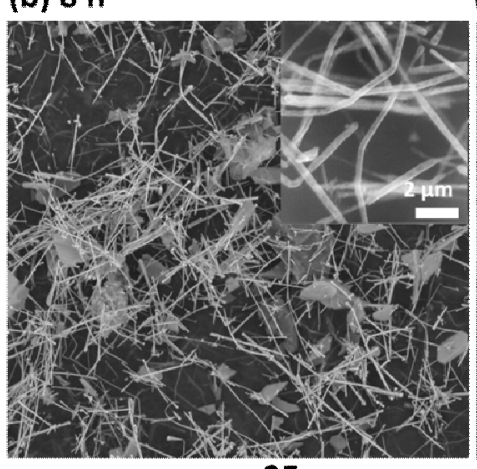

$25 \mu \mathrm{m}$ (c) $12 \mathrm{~h}$

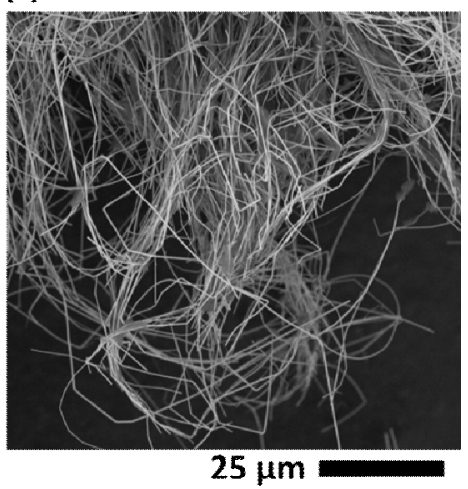

Figure 1. SEM images of $\mathrm{Cu}$ NWs prepared by hydrothermal method using $0.6 \mathrm{mM} \mathrm{OA}$ at $120^{\circ} \mathrm{C}$ at 4,8 , and $12 \mathrm{~h}$ respectively.

Figure 2 shows the XRD patterns of the synthesized products. At $4 \mathrm{~h}$, peaks at $42.5,61.5$, and $74^{\circ}$ correspond to the 200, 220 and 311 plane of $\mathrm{Cu}_{2} \mathrm{O}$ (JCPDS card no. 05-0667). A shoulder peak at 43.5 is observed at $4 \mathrm{~h}$, indicating the formation of metallic copper. After $12 \mathrm{~h}$, only peaks at $43.5,51$, and 74.5 which correspond to 111 , 200, and 222 planes of copper (JCPDS card no. 85-1326) are observed. Using Scherrer's equation, the crystallite size was determined to be $3.51 \mathrm{~nm}$ for $\mathrm{Cu}_{2} \mathrm{O}$ using the 200 plane, and $8.94 \mathrm{~nm}$ for $\mathrm{Cu}$ using the 111 plane.
Figure 3 shows the SEM images of $\mathrm{Cu}$ NWs prepared using varying amounts of oleic acid. At $0.6 \mathrm{mM}$ oleic acid, very thin nanowires $(\sim 72.33 \mathrm{~nm})$ were present. However, these were combined with tetragonal and spherical nanoparticles even after $12 \mathrm{~h}$. Increasing the oleic acid concentration to $1.2 \mathrm{mM}$ led to the formation of smooth wires that are able to withstand torsion (Fig. 3b, inset). Further addition of oleic acid produced faceted wires with rigid sides. All the $\mathrm{Cu}$ NW products easily exceed $200 \mu \mathrm{m}$ in length and do not exhibit tapering along the entire length.

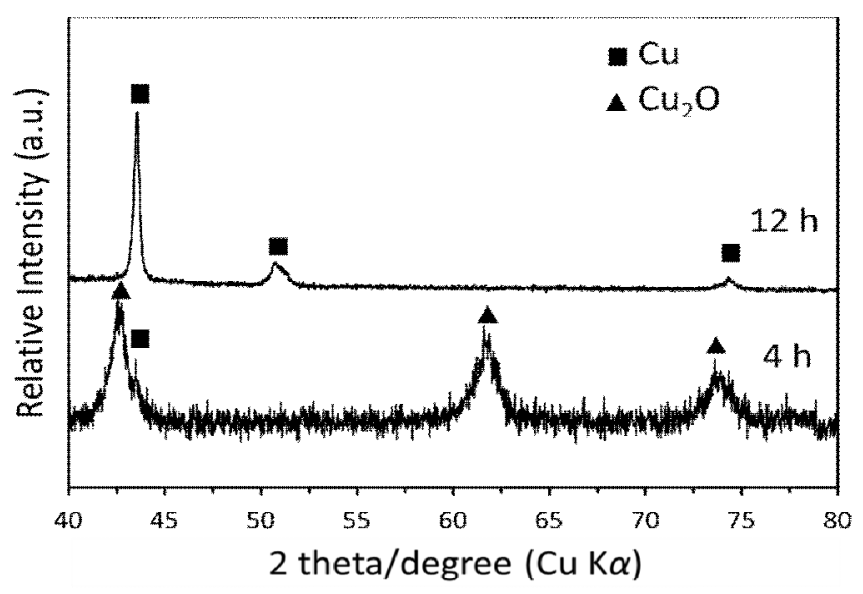

Figure 2. XRD patterns of $\mathrm{Cu}$ nanowires prepared by hydrothermal synthesis using $.6 \mathrm{mM}$ oleic acid at $120^{\circ} \mathrm{C}$ after 4 and $12 \mathrm{~h}$ respectively. 
(a) $0.6 \mathrm{mM}$

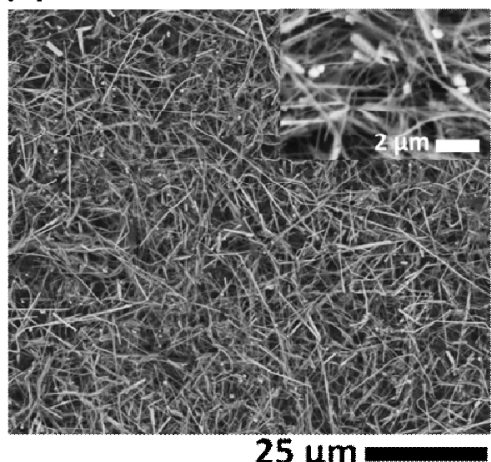

$25 \mu \mathrm{m}$ (b) $1.2 \mathrm{mM}$

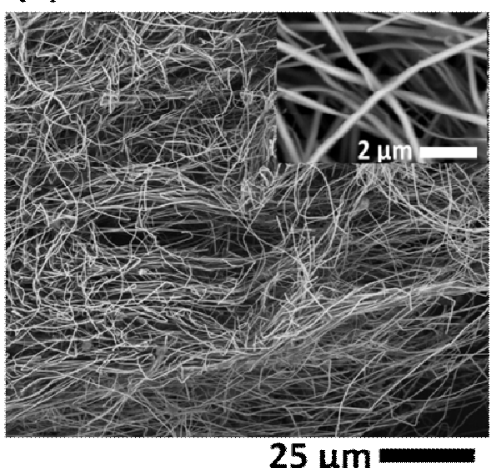

(c) $1.8 \mathrm{mM}$

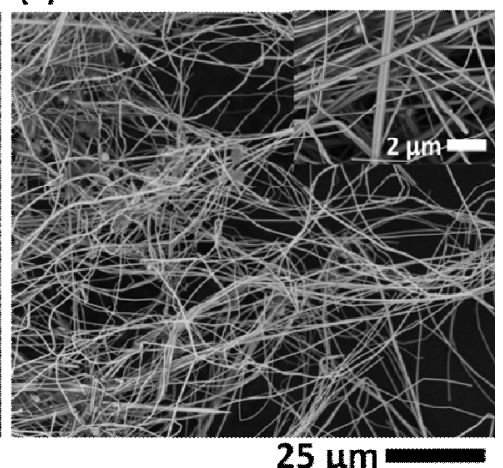

Figure 3. SEM images of the $\mathrm{Cu}$ NWs prepared by hydrothermal synthesis for $12 \mathrm{~h}$ at $120^{\circ} \mathrm{C}$ using (a) 0.6 , (b) 1.2 , and (c) $1.8 \mathrm{mM}$ oleic acid.

High resolution TEM (HRTEM) images indicate that the $\mathrm{Cu}$ NWs appear to be very smooth and uniform in diameter as shown in Fig 4a (inset). The measured diameter was found to be $76.8 \mathrm{~nm}$ which corresponds well to the average diameter taken from SEM images. The preferred growth direction was found to be along the [1-10] as shown in Fig 4a. The selected are electron diffraction (SAED) pattern obtained from the $\mathrm{Cu}$ NW indicates two sets of diffraction patterns which can be assigned to the [110] and [111] zone axes of facecentered cubic (fcc) structure as shown in Fig. 4b. The superimposed pattern signifies a five-fold twinned pentagonal structure which was found to be a significant factor in the nanowires' ability to withstand torsion and bending [8].

The presence of $\mathrm{Cl}^{-}$ions was found to be critical in promoting anisotropic growth. The absence of $\mathrm{Cl}^{-}$leads to the formation of faceted octahedron and spherical crystals with a large variation in the sizes ranging from $500 \mathrm{~nm}$ to
$2 \mu \mathrm{m}$ as shown in Fig 4d. The facets may be due to planar defects on the surface of the crystals. The initial ageing of the precursor solution at $50^{\circ} \mathrm{C}$ for $12 \mathrm{~h}$ was found to be a necessary step in the reaction process. During ageing, the OM complexes with the $\mathrm{Cu}^{2+}$ ion. Initially, the $\mathrm{OM}$ was imiscible in the solution, but as the solution was heated, and vigorous stirring was employed, the color changed from royal blue to avocado green after about $6 \mathrm{~h}$ as shown in Fig $4 \mathrm{c}$ and inset. The royal blue color at the beginning of the reaction indicates the presence of free $\mathrm{Cu}^{2+}$ in the mixture. After $12 \mathrm{~h}$, the OM became fully soluble in the solution and the change in color may indicate complexation of $\mathrm{OM}$ with the $\mathrm{Cu}^{2+}$ ion. In this system, the OM selectively binds at the $\{111\}$ plane, which has the highest surface energy among fcc planes. As a result, the presence of OM restricts further addition of $\mathrm{Cu}$ atoms along the [111] plane and subsequent $\mathrm{Cu}$ reduction occurs along the [110] direction.

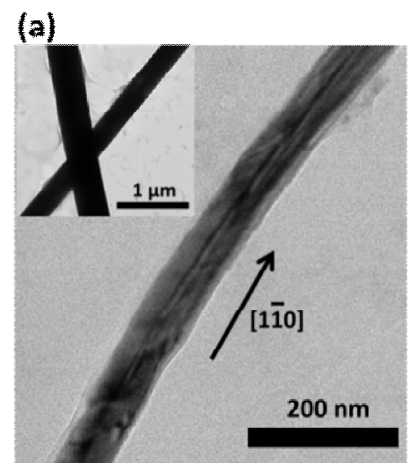

(b)

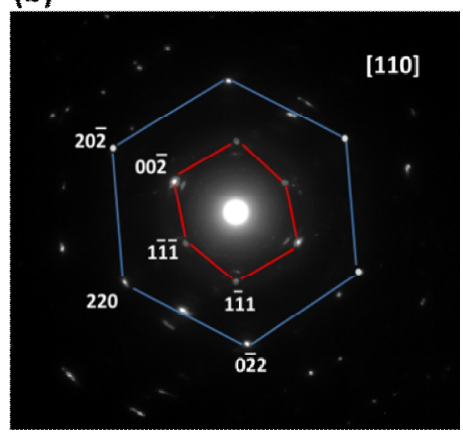

(c)

(d)

$2 \mu \mathrm{m}$
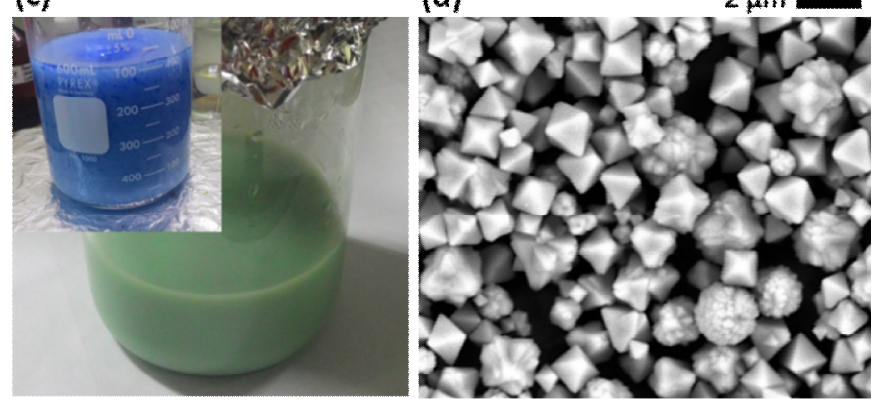
Figure 4. (a) HRTEM images showing smooth and uniform NWs produced using $1.8 \mathrm{mM} \mathrm{OA}$ at $120^{\circ} \mathrm{C}$ for $12 \mathrm{~h}$ and its growth direction along the [1-10] plane. (b) Corresponding SAED pattern shows a five-fold twinned pentagonal structure. (c) Precursor solution before (inset) and after $12 \mathrm{~h}$ of stirring at $50^{\circ} \mathrm{C}$ showing a change in color. (d) $\mathrm{Cu}$ microcrystals products formed when $\mathrm{CuCl}_{2}$ was replaced with $\mathrm{Cu}\left(\mathrm{NO}_{3}\right)_{2}$ salt using $1.2 \mathrm{mM} \mathrm{OA}$ at $120^{\circ} \mathrm{C}$ for $12 \mathrm{~h}$.

At the start of the reaction, the $\mathrm{Cu} 2+$ ion is oxidized to $\mathrm{Cu} 2 \mathrm{O}$ seeds in the presence of water at high pressure and temperature as evidenced by corresponding $\mathrm{Cu} 2 \mathrm{O}$ peaks in the XRD (Fig. 2a). However, the presence of an etchant such as $\mathrm{Cl}$ - ions, selectively etches the oxide seeds present in the solution through a process known as oxidative etching [9]. In order to ascertain the role of $\mathrm{Cl}$-, the $\mathrm{CuCl} 2$ precursor was replaced with equal molar $\mathrm{Cu}(\mathrm{NO} 3) 2$. When $\mathrm{Cu}(\mathrm{NO} 3) 2$ was used, $\mathrm{Cu}$ octahedral crystals were formed instead of $\mathrm{Cu}$ NWs. As such, in the absence of an etchant, the seed crystals will continue to grow to form faceted crystals as shown in Fig 4d.

As the reaction continues, the octahedral $\mathrm{Cu} 2 \mathrm{O}$ seeds are etched back to form $\mathrm{Cu} 2+$ ions. These ions are then preferentially reduced in the presence of glucose along the [110] direction. However, when the amount of OA required to coordinate with the freed $\mathrm{Cu} 2+$ is insufficient, the ions are eventually reduced by glucose and form spherical and irregular shaped particles instead, as shown in Fig 3a. Regardless, only metallic $\mathrm{Cu}$ products remain after $12 \mathrm{~h}$ reaction suggesting that the presence of glucose will eventually reduce the $\mathrm{Cu} 2 \mathrm{O}$ seeds even in the absence of an etchant.

The complementary etching and reducing reactions take place simultaneously during the process. This is further shown in the decrease of tetragonal structures found in Fig. 1a and subsequent formation of more wires in Fig. 1b,c. With sufficient coordination, all the initial $\mathrm{Cu} 2 \mathrm{O}$ seeds are completely etched and only $\mathrm{Cu}$ wires remain after $12 \mathrm{~h}$. This XRD patterns also agrees well with the proposed formation mechanism.

The OA increases the coordination of the $\mathrm{Cu}$ along the [111] plane. The OA has a similar alkyl chain with OM, but the amine at the end is replaced with a hydroxyl functional group. This allows it to selectively bind with $\mathrm{Cu} 2+$ without being an electron donor. As such, it can increase the coordination of the ions without affecting the overall reduction kinetics. As more OA is added, the wires become cylindrical (Fig 3b, inset) and cubic (Fig 3c, inset) due to the increase in the overall coordination.

\section{Summary}

In summary, $\mathrm{Cu}$ NWs with lengths exceeding $200 \mu \mathrm{m}$ and an average diameter of $82.3 \mathrm{~nm}$ were synthesized through an oleylamine-assisted, hydrothermal method for $12 \mathrm{~h}$ at $120^{\circ} \mathrm{C}$. XRD peaks at 4 and $12 \mathrm{~h}$ confirmed that the $\mathrm{Cu}^{2+}$ was initially oxidized to $\mathrm{Cu}_{2} \mathrm{O}$ before being fully reduced to metallic copper. The wires easily reach an aspect ratio $>1000$ and can withstand bending and torsion. In the absence of $\mathrm{Cl}^{-}$, crystal growth was observed, which indicates the importance of $\mathrm{Cl}^{-}$as an etchant for anisotropic growth.

\section{Acknowledgment}

This study was supported by the Department of Science and Technology-Philippine Council for Industry, Energy and Emerging Technology Research and Development (DOST-PCIEERD) Department of Science and Technology-Engineering Research and Development for Technology (DOST-ERDT) and University of the Philippines under the Office of the Vice-Chancellor for Research and Development (PhD Incentive Award).

\section{References}

1. D. Zhang, R. Wang, M. Wen, D. Weng, X. Cui, J. Sun, H. Li, Y. Lu, Journal of the American Chemical Society 134, 14283-14286 (2012)

2. Y. Won, et al., NPG Asia Materials 6, (2014)

3. I. Stewart, A.R. Rathmell, L. Yan, S. Ye, P. Flowers, W. You, B. Wiley, Nanoscale 6, 5980-5988 (2014)

4. Z. Liu, Y. Yang, et. al., Journal of physical Chemistry B 107, 12658-12661 (2003)

5. Y. Chang, M. Lye, H. Zeng, Langmuir 21, 37463748 (2005)

6. B. Wiley, Chemical Communications 50, (2014)

7. R.L. Graham, et al., Applied Physics Letters 96, 2116 (2010)

8. H.J. Yang, S.Y. He, H.Y. Tuan, Langmuir 40, 602610 (2014)

9. R. Long, et al., Chemical Society Review 43, 62886310 (2014) 